\title{
Effectiveness of Mobile Marketing System to Improve the Potential of MSMEs using Location-based Service System
}

\author{
Fiftin Noviyanto \\ Department of Informatics Engineering \\ Faculty of Industrial Engineering, \\ Ahmad Dahlan University
}

\author{
Merlinda Wibowo \\ Department of Computer Science \\ Faculty of Computing \\ Universiti Teknologi Malaysia
}

\begin{abstract}
Enhancement in marketing of Micro, Small and Medium Enterprises (MSMEs) have constraints especially limitations on publication of information to prospective buyers, for example, business location, type of product and the selling price. The solution to these problems is the manufacturing of mobile marketing system by following the existing business processes. But the application has not been implemented and tested on the level of effectiveness thus has not been known for application success rate. In this research will do the implementation of existing technologies and then measure the growth rate of the marketing potential of MSMEs. The testing conducted with the involvement of the community (the prospective buyer of the product MSMEs) in the ease of accessing information. System effectiveness was tested using pre- and post-test. The result of this research is the application of the system of location based services for mobile marketing MSME products that provide detailed information on the products offered and IRM concept to measure the performance of the device on resource management. The testing of the results show that the system of knowledge of the potential buyers of the products of MSMEs increased to $91.2490 \%$ after using this system.
\end{abstract}

\section{Keywords}

Software Testing, MSMEs, Location Based Services System, Pre- and Post- Test, T-Test.

\section{INTRODUCTION}

The constraint of Micro Small and Medium Enterprises (MSMEs) development located in the scope of the publication of information to potential buyers. Efforts to introduce the product and the location of MSMEs in Yogyakarta have been done by following exhibitions of MSMEs that organized by the Communication Forum of City's Government. The scope of marketing and efforts to expand the area of marketing has been done by Merlinda [1] with develop the Barukamu applications based on android native mobile. But the result of the application has not been applied in the existing research. So it has not seen the results and impact on expanding the publication of the information.

Technology mobile has become a technology that rapidly growing and popular form year to year. The mobile devices subscriptions at the global level are almost seven and from developing country [2]. According to International Data Corporation (IDC) Asia or the Pacific Quarterly Mobile Phone Tracker, Indonesia mobile phone market growth has been recorded the number of unit shipments in the third quarter totaled 15.5 million units or growing $13 \%$ on a quarter-on-quarter (QoQ) and $14 \%$ in year-on-year (YoY) [3]. If refers to the IDC data that has been presented before, the development of mobile technology in Indonesia at this time can be said to be growing rapidly, thus spurring increased also on improving the facilities and services to support these developments. But there are still many MSMEs, especially micro-enterprises in the city of Yogyakarta has not been published their products in online system because of limited knowledge that related to computer technology. The optimization of the development of mobile marketing technology can be utilized to realize Mobile Product Marketing for Micro, Small and Medium Enterprises (MSMEs).

The migration process replacing the old system with a new system that has its own difficulties in addition to the problem of data processing [4] [5] and also trust problems of potential users to change old habits that are already running [6] [7]. Need to do a preliminary study that can provide information on eligibility application of the new system. There is several software testing techniques to ensure the new system fit for use [8].

In this research, the performed tests involving prospective buyers of MSMEs from various communities. Further analysis of the results obtained using the T-Test. The test results by a reference to the feasibility of Mobile Marketing System to expand the publication of information MSMEs.

\section{MATERIALS AND METHODS}

This research is related to the feasibility of the mobile marketing system implementation refers to a previous study by Merlinda [1] which produces software-based Native Barukamu mobile, which has not been implemented. The result of existing studies is the design of a mobile application for MSMEs promotion which used the location-based service but cannot provide recommendations on the feasibility of applying the system to increase the potential of MSMEs. Several studies using the technique of Location-based Services (LBS) have also been done before [9]. The study has been implementing with location-based service system on Android operating system, LBS access and application filtering to keep users' privacy. [10]

Other studies related to SMEs have been carried out by Fernando, et al [11] which resulted in the application for ordering and distribution of products. In addition, some research on the study of the distribution of MSMEs and cluster assessment had been carried out [12]. In addition, research on the efficiency of product distribution MSMEs conducted by Kuswantoro, et al. [13]

Research that has been done has resulted in outcomes in the form of an analysis assessing the potential of SMEs, software to assist the publication and distribution of information, but has not done a feasibility test for the application of the system. 
FASE 1
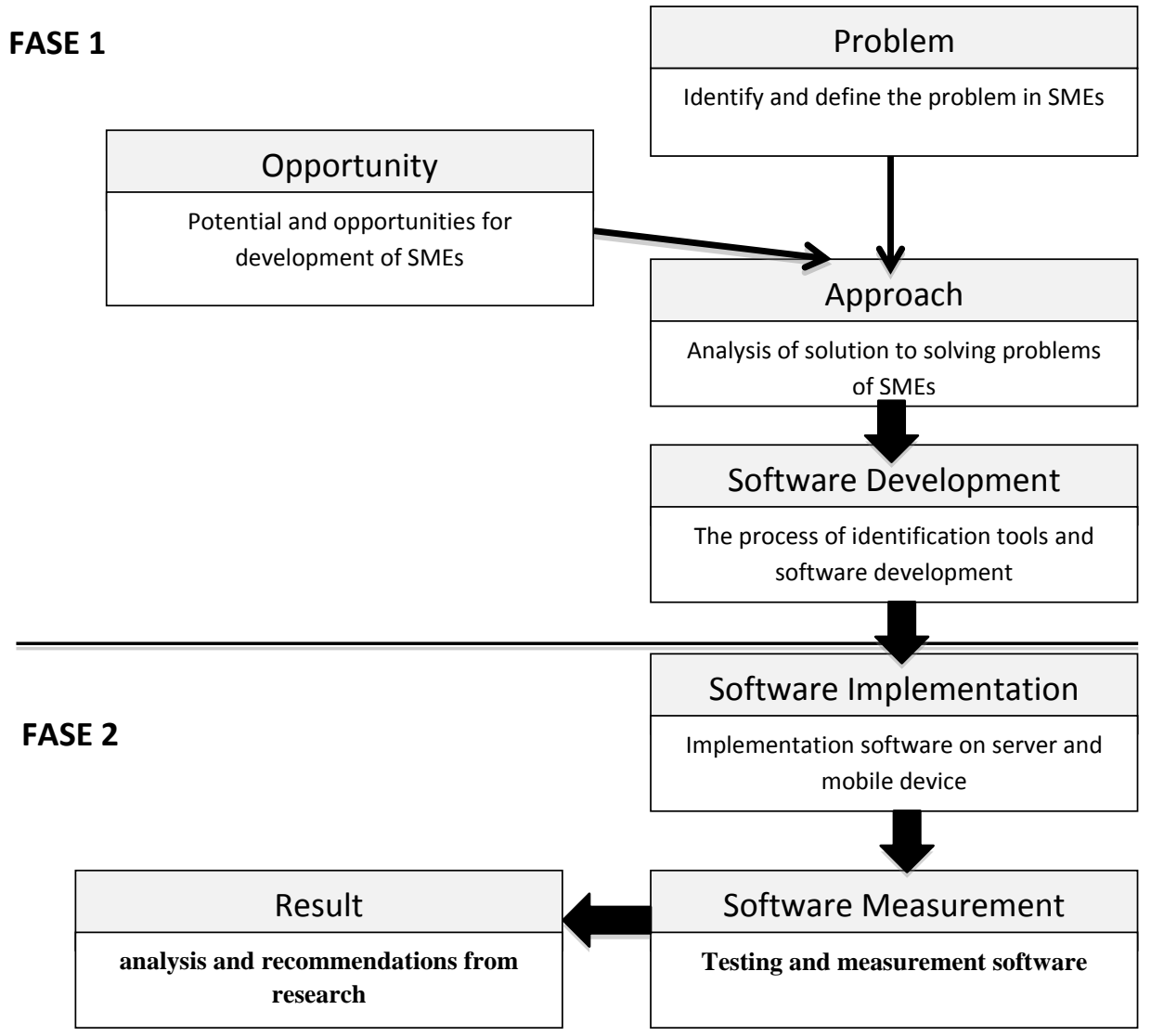

Fig 1. Research methodology

Figure 1 shows the development of mobile marketing for increase the potential of MSMEs has been carried out using location-based services through phase 1: software development. Furthermore, this reseach will proceed to phase 2: software implementation to produce the desired result.

\subsection{Determination of Problems}

In the framework of existing research in Figure 1, it can be seen that the lines of inquiry start from defining the problems that exist in this study, namely the MSMEs promotion products that still limited in the MSMEs exhibition. The location of SMEs which are widespread in the city of Yogyakarta and make buyers difficulties in finding the desired business centers. Development of the system is using a flowchart to design how the process is running and using Black Box and White Box for testing. The implementation in this research is development of the system and perform measurements that provide pretest-posttest to measure improvements before and after using Location-Based Service System for Mobile Product Marketing, Micro, Small and Medium Enterprises (MSMEs).

\subsection{Solution Approach}

In this phase is needs analysis system to solve the existing problems. Based on the existing problems, has been formulated a system that could be the focus of settlement, namely: mobile marketing and location-based systems. The system developed features, as follows:

a. System can provide information list or a list of MSMEs who are nearby.

b. System can provide location information and route path of the user's location at the time to the location of SMEs who want to visit.

c. System can provide detailed information about the targeted MSMEs, such as a brief explanation of MSMEs, phone numbers, addresses, and products offered.

d. Owners of MSMEs can manage data on a web server. The management of the data in web service includes data input, edit data and delete data MSMEs. In addition, MSME owners can view the list of the data previously entered MSMEs. Data will be converted into JSON data for make it easier to the parsing data in the user's smartphone. 


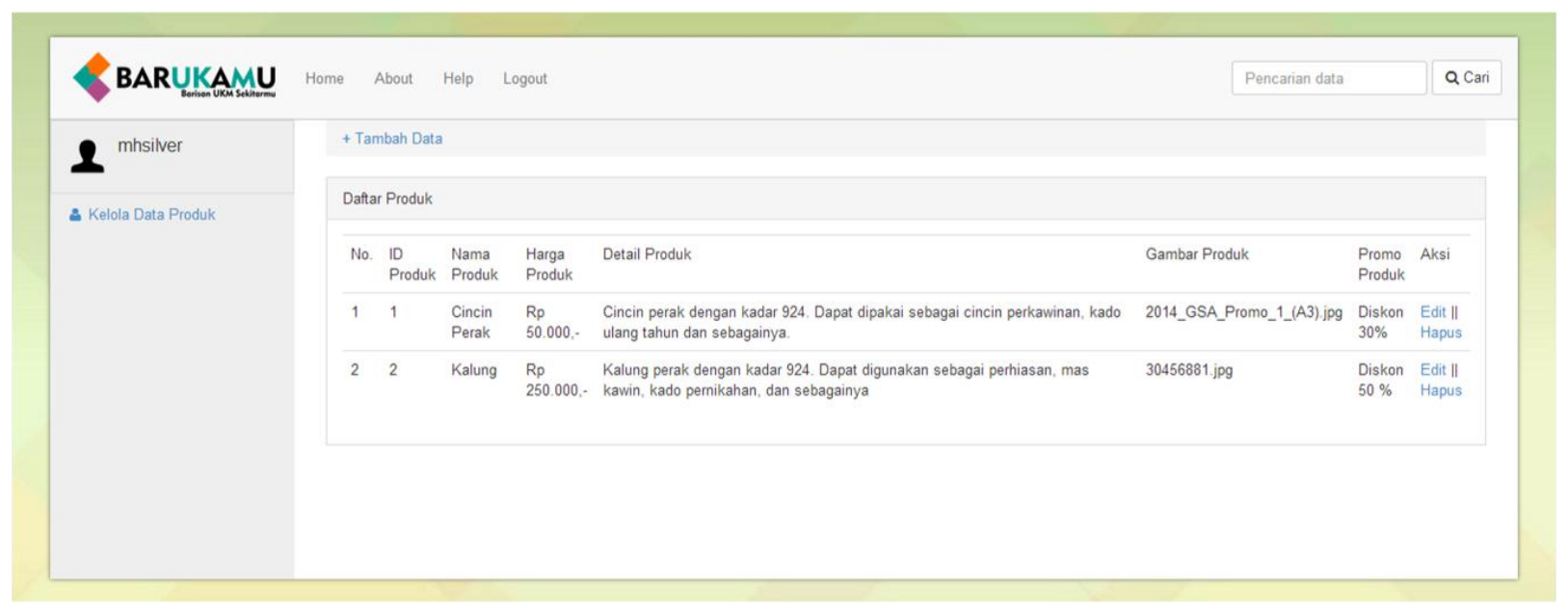

Fig 2. Web page in Web Service

\subsection{Development and Implementation System}

\subsubsection{MSMEs Owner}

MSMEs owner is become a manager in the backend systems to access and manage data through web pages in web service. All data in the server database will be converted into JSON data that is subsequently used to facilitate the distribution of information to users using Android smartphone to access the Barukamu application. To display JSON data exist, can be seen in Source Code 1.

data['datadata'] $\leftarrow$ this->model_home->getDataJson ()
write json_encode(data)

\section{Source Code 1. Displaying Data JSON}

Figure 2 will be shown the web page in web server for data management of the MSMEs data.

\subsubsection{System to the Public Users}

The application named Barukamu has been developed to help the public community to access the application based on native mobile. This application has been built based on android and location-based services system for mobile marketing MSMEs product. The application takes the JSON data from a web service that had been established earlier to display information to the user. Information provided to the user in the form of a list of MSMEs and their products. JSON data retrieval process can be seen in Source Code 2

// Creating service handler class instance
ServiceHandler sh $\leftarrow$ new ServiceHandler()
// Making a request to url and getting response
String jsonStr $\leftarrow \quad$ sh.makeServiceCall(url,
ServiceHandler.GET)

Source Code 2. Getting Data JSON

In Figure 3 can be seen views of SMEs and their products from the list of data retrieval from the web service.

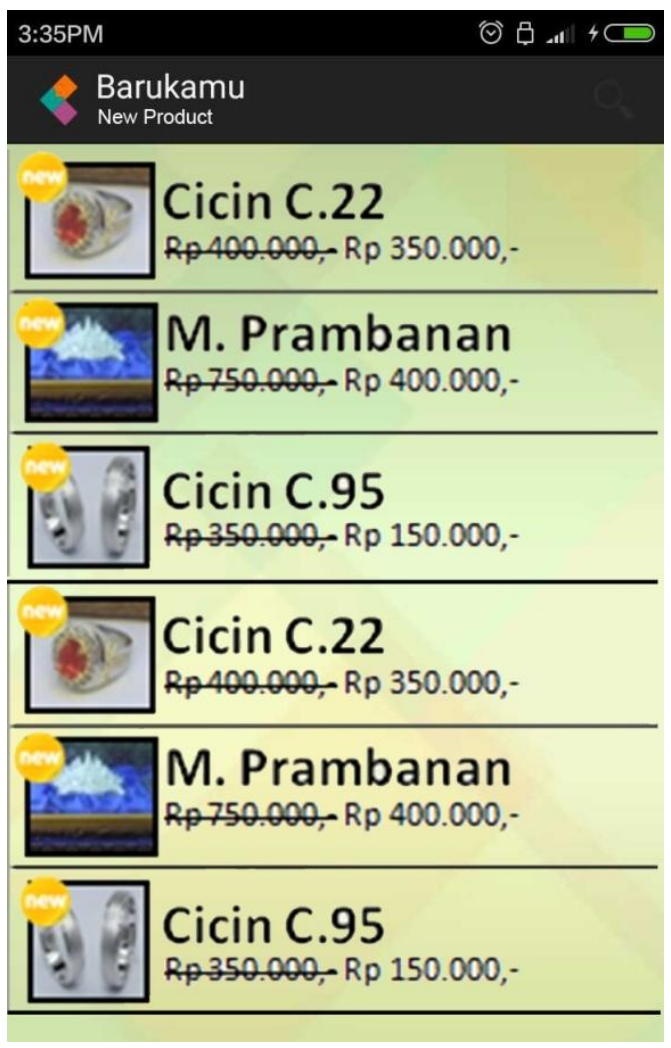

Fig 3. Display List of SMEs and their products

\section{EXPERIMENTAL RESULTS}

The system has been developed will be tested and measured for the effectiveness factor. Measurement is an indicator or a measuring tool to see the knowledge of prospective buyers of the product and the location of MSMEs before and after from this system.

\subsubsection{Pre- and Post Test}

Pre- and post- test provided in the form of the answer sheet to the user of the application and the given problem is same. From the results obtained was made a graph to compare the knowledge of the prospective buyers and the location of MSMEs. The knowledge comparison of the prospective of product buyer and the location of MSMEs using LocationBased Services System for Mobile Marketing MSME products can be seen in figure 4 . 


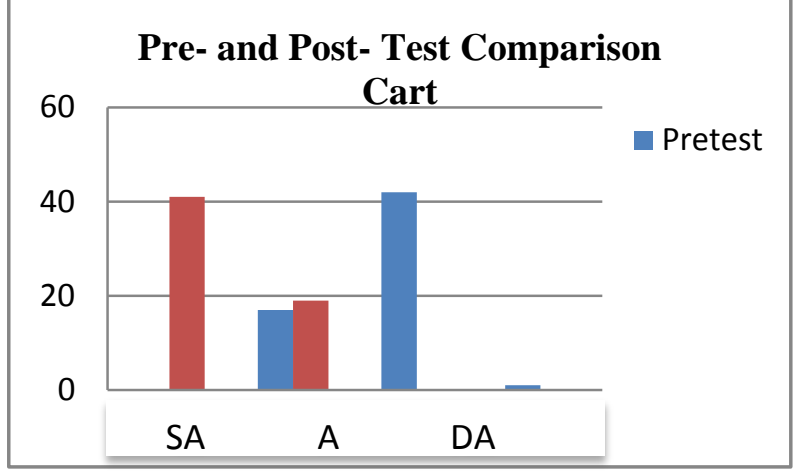

Fig 4. Comparison Pre- dan Post Test Graphic

(SA: Strong Agree A: Agree DA: Disagree SD: Strong Disagree)

In Figure 4 it can be seen that the knowledge level of the potential buyers of the product and the location of MSMEs after using Location-Based Service System for Mobile Marketing MSME products is increased.

\subsubsection{T-Test}

$\mathrm{T}$-Test were used in this study were paired T-test (two independent variables). T-Test paired performed to examine differences in knowledge gaps prospective buyers of the product and the location of MSMEs before and after using the System Location-Based Services for Mobile Marketing MSME products that utilize the concept of Intelligent Resource Monitor (IRM). Testing was conducted using SPSS 16. The results of the value pretest and posttest questionnaire respondents is shown in Table 1 .

Table 1. Results of Prospective Buyers Knowledge Test Values Pre- and Post- Test

\begin{tabular}{|c|c|c|}
\hline $\begin{array}{c}\text { Responden } \\
\text { (prospective } \\
\text { buyers) }\end{array}$ & $\begin{array}{c}\text { Before } \\
\text { implementation } \\
\text { mobile } \\
\text { marketing SME's } \\
\text { application }\end{array}$ & $\begin{array}{c}\text { After } \\
\text { implementation } \\
\text { mobile marketing } \\
\text { SME's application }\end{array}$ \\
\hline 1 & 54.17 & 83.33 \\
\hline 2 & 66.67 & 83.33 \\
\hline 3 & 62.50 & 83.33 \\
\hline 4 & 58.33 & 100.0 \\
\hline 5 & 62.50 & 95.83 \\
\hline 6 & 50.00 & 95.83 \\
\hline 7 & 62.50 & 91.67 \\
\hline 8 & 54.17 & 85.50 \\
\hline 9 & 50.00 & 100.0 \\
\hline 10 & 45.83 & 91.67 \\
\hline
\end{tabular}

\section{CONCLUSION}

The problems are solved in this study, it is the difficulties of people finding the location of MSMEs and information for the related products. This research implements mobile marketing with location-based services and testing the feasibility of this system.

The results from data processing and testing by using pretest and post-test with SPSS 16 tool and Paired Sample T-Test can be seen that there are differences in the average (mean) value of knowledge potential buyer after using the application of 91.2490. Turns $\alpha=0.05$ is smaller than the value of Sig or [0.05<0.449], then Ho is accepted and Ha rejected. This means that there is an increase in the value of knowledge of the potential buyer after using location-based services system for mobile marketing MSME products.
The future of this research we will work with big data analytics. We know the data will increase in time by time. Big data also become a big trend in the next periode.

\section{ACKNOWLEDGMENTS}

Our thanks to Resource Development of Micro, Small and Medium Enterprise (MSME), Department of Industry has provided research support information and thanks to SME's Owner in Yogyakarta.

\section{REFERENCES}

[1] M. Wibowo and H. Yuliansyah, "Location Based Service Application Design for Mobile Promotion SME 's Product and the Nearest Bank Service Information," in International Conference on Green World in Business and Technology 2014, 2014, pp. 98-106.

[2] ITU, 2014. The World in 2014, ICT Facts and Figure ITU.

[3] A. Saraswati, "Android Extends OS Market Share as Indonesians Go 'Smart,"” 2012. [Online]. Available: http://cdn.idc.asia/files/e95a442d-4d20-444e-93478e7b11b0a21f.pdf. [Accessed: 22-Nov-2016].

[4] L. Rintamäki, "Data migration , a practical example from the business world Master of Science Thesis in Software Engineering and Technology," University of Gothenburg, 2010.

[5] M. R. Girgis, A. I. El-Nashar, T. A. A. El-Rahman, and M. A. Mohammed, "An ASP.NET Web Applications Data Flow Testing Approach,” Int. J. Comput. Appl., vol. 153 , no. 8, pp. 6-18, Nov. 2016.

[6] A. Josang, R. Ismail, and C. Boyd, "A Survey of Trust and Reputation Systems for Online Service Provision," Decis. Support Syst., vol. 43, pp. 618-644, 2007.

[7] W. Sherchan and C. Paris, "A Survey of Trust in Social Networks," ACM Comput. Surv., vol. 45, no. 4, pp. 133, 2013

[8] S. S. R. Ahamed, "STUDYING THE FEASIBILITY AND IMPORTANCE OF SOFTWARE TESTING : AN ANALYSIS,” Internatinal J. Eng. Sci. Technol., vol. 1, no. 3, pp. 119-128, 2009.

[9] A. Kushwaha and V. Kushwaha, "Location Based Services using Android Mobile Operating System," vol. 1, no. 1, pp. 14-20, 2011.

[10] S. Yadav, "Improved the Location Privacy Preserving Method in Location based Services using Modified Bloom Filter," vol. 154, no. 11, pp. 31-36, 2016.

[11] M. J. E. Fernando, S. S. Shurane, L. S. Wijesinghe, N. M. Thenuwara, and D. Dhammearatchi, "Pick My Dress: Beacon based Navigation System to find your Suitable Wear,” Int. J. Comput. Appl., vol. 154, no. 1, pp. 16-20, Nov. 2016.

[12] S. A. Anton, I. Muzakan, and W. F. Muhammad, "An Assessment of SME Competitiveness in Indonesia," vol. 7, no. 2, pp. 60-74, 2015.

[13] K. Bharu and R. A. Kader, "Innovation in Distribution Channel, Cost Efficiency \& Firm Performance: The Case of Indonesian Small \& Medium Enterprise Scales," vol. 2, no. 4, pp. 23-38, 2012. 